\title{
Development of geothermal field following the 2000 eruption of Usu volcano as revealed by ground temperature, resistivity and self-potential variations
}

\author{
Mizue Saba $\left({ }^{1}\right)$, Yasunori Nishida $\left({ }^{1}\right)$, Toru Mogi $\left({ }^{1}\right)$, Shin'ichi Takakura $\left({ }^{2}\right)$ and Nobuo Matsushima $\left({ }^{2}\right)$ \\ $\left.{ }^{(}\right)$Institute of Seismology and Volcanology, Faculty of Science, Hokkaido University, Sapporo, Japan \\ $\left.{ }^{2}{ }^{2}\right)$ The Geological Survey of Japan, The National Institute \\ of Advanced Industrial Science and Technology (AIST), Tsukuba, Japan
}

\begin{abstract}
The 2000 eruption of Usu volcano, NE Japan, took place on the foot of the somma, and formed a cryptodome of $65 \mathrm{~m}$ high accompanying numerous faults. We made repeated measurements of ground temperature, Self-Potential (SP) and electrical resistivity, in order to clarify the mechanism of development of the newly formed geothermal field on the fault zone. Prior to the expansion of the geothermal field, we detected a resistive zone at the center of the geothermal zone and it supposed to evidence that the zone involving dry steam phase had been formed beneath the fault zone. A rapid expansion of the geothermal field followed along the fault zone away from the craters. The place of maximum amplitude of the SP field also migrated following the expansion of the high ground temperature zone. The high resistive part has shrunk as a consequence of the progress of condensation to warm the surroundings. Based on the observations, we delineated the process of the hydrothermal circulation. Considering the topographic effect of the SP field observed on the highly permeable zone in the Usu somma, the potential flow along the slope of the soma was expected to play an important role to promote the rapid expansion of the geothermal field and the migration of the most active part.
\end{abstract}

Key words Usu volcano - geothermal field ground temperature - electrical prospecting - selfpotential field - hydrothermal circulation

\section{Introduction}

The thermal energy from eruption cloud and steaming ground is dominant in comparison with others such as seismic wave, momentum of ejec-

Mailing address: Prof. Toru Mogi, Institute of Seismology and Volcanology, Faculty of Science, Hokkaido University, Sapporo 060-0810, Japan; e-mail: mogitsv@ mail.sci.hokudai.ac.jp ta etc. in the energy release process accompanied by volcanic activity (e.g., Izu-Oshima Miharayama: Yokoyama, 1957; Sheveruchi: Tokarev, 1967). Through the geothermal study of the 1977-1978 eruption of Usu volcano, Matsushima $(1992,2003)$ proved that the thermal energy release by the eruption cloud was predominant during the eruption stage, but it decayed sharply after the eruption ceased. Instead, the energy release from the steaming ground becomes superior to that from the eruption cloud. Therefore, it is important to study the formation process of steaming ground from the volcano-energetic point of view. Zohdy et al. (1973) and subsequent scientists have studied geothermal systems using the electrical method because the hydrological and thermal environments are 
strongly sensitive to the electrical properties of a geothermal field. We monitored temporal variations of the Self-Potential (SP) and resistivity as well as ground temperature on the newly formed Nishiyama geothermal field following the 2000 eruption of Usu volcano to pursue the expansion and decay process of steaming ground.

Usually, geothermal fields following volcanic eruptions have developed on the existing geothermal fields. In the present case, however, the Nishiyama geothermal field has developed over the foot of the Usu volcano which has shown no geothermal indication in the past. Therefore, we encountered a good opportunity to study an evolution of new geothermal field, especially in the early stage of geothermal activity, without disturbance of the existing geothermal field. We report the results of the obser- vations and propose a qualitative model of the steaming ground in this paper.

\section{Geological setting and brief sketch of the 2000 eruption of Usu volcano}

\subsection{General explanations of Usu volcano}

Usu volcano is one of the most active volcanoes in Japan and is located at the south edge of Toya caldera, Hokkaido (fig. 1). On the summit crater of Usu $(1.6 \times 1.8 \mathrm{~km}$ in diameter $)$, two dacitic lava domes (O-Usu and Ko-Usu in fig. 1), a cryptodome and faults are distributed. The eruptions of Usu volcano were reported nine times from 1663, and occurred every several tens of years in the 20th century. These eruptions were characterized by extrusion of viscous fel-

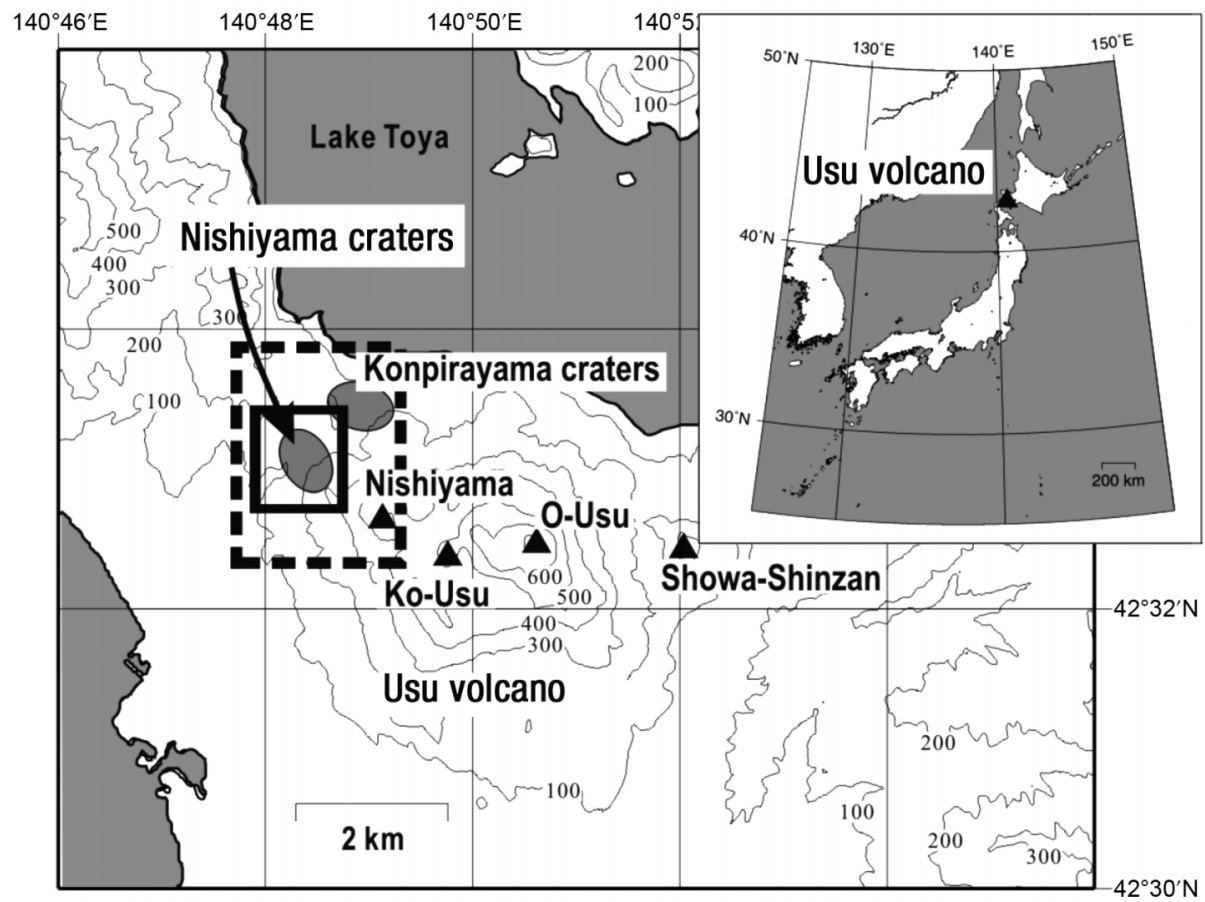

Fig. 1. Topographic map in and around Usu volcano. Contour interval is $100 \mathrm{~m}$. Solid triangles represent two lava domes (O-Usu and Ko-Usu) formed in the past activities. Nishiyama is a topographic high of the Usu somma. The 2000 eruptions of Usu occured within the dashed square. The present study is focused on the solid square region. 


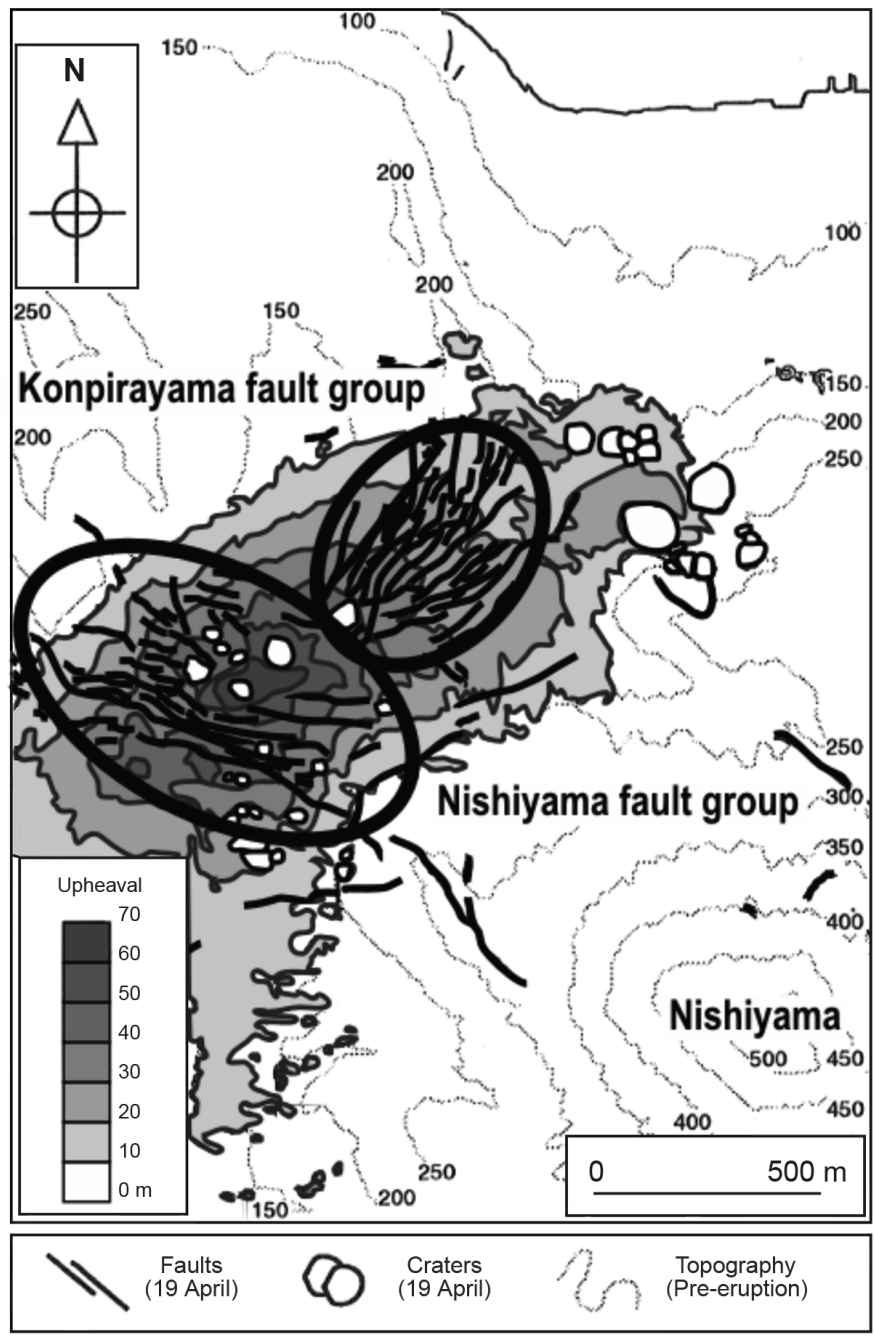

Fig. 2. Distribution of newly formed craters, faults, and a cryptodome (shaded part). The upheaval data of the cryptodome were measured on 26 April, 2000 (after unpublished data of Public Works Research Institute). Distribution of the faults and craters was investigated on 19 April, 2000 (modified after Miura and Niida, 2000).

sitic magma and formation of lava domes and cryptodomes (Nakagawa et al., 2005).

\subsection{The 2000 eruption of Usu volcano}

Various phenomena accompanied by the 2000 eruption of Usu took place mainly on the region shown in fig. 2 , and the time sequence of volcanic activities was divided into three stages (Ui et al., 2002).

Precursory stage - In March 27, 2000, a local earthquake swarm occurred beneath the Usu volcano. Then the earthquakes increased in frequency and intensity. Some of them were strong enough to be felt in the whole area around Usu, 


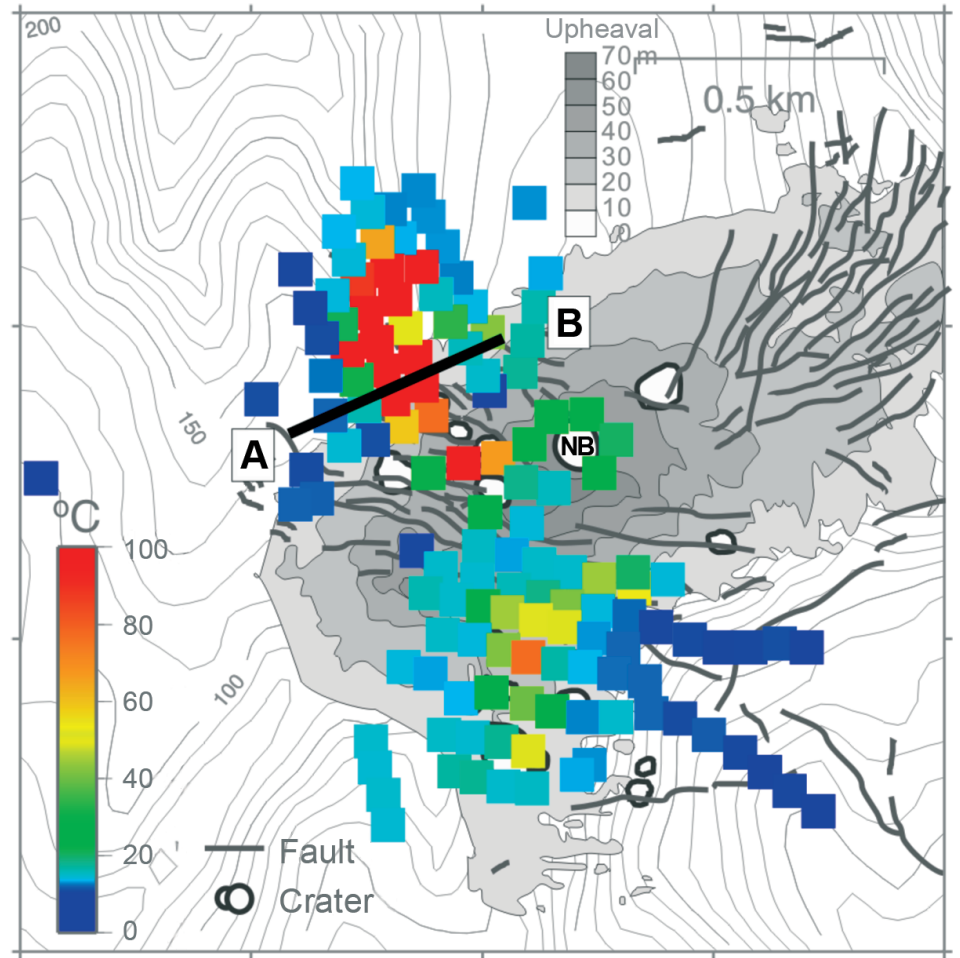

Fig. 3. Distribution of the ground temperature in $1 \mathrm{~m}$ depth measured in October-November, 2000. A-B denotes the measurement line.

up to about $220 \mathrm{~km}$ from the volcano. Several fissures and cracks were formed on the crater floor of the summit and the western foot of the somma.

Eruption stage - The eruption started at the western flank of Usu volcano in March 31, 2000 after 23 years of dormancy since the 1977-1978 activities. A vigorous ash column rose up to 2.3 $\mathrm{km}$ high in maximum. Eruptions were phreatomagmatic and small craters were formed mainly around the west to northwest side of Nishiyama, which is a cryptodome on the Usu somma, and the north foot of the somma. These were named Nishiyama crater group and Konpirayama crater group, respectively (fig. 1). Eruptive activity of the Nishiyama crater group finally converged to NB crater shown in fig. 3 . As the eruptive activity proceeded, numerous fissures and faults were formed in a NW-SE direction (Nishiyama fault group) and NE-SW direction (Konpirayama fault group) as shown in fig. 2. At the same time, the Nishiyama fault group region uplifted to form a cryptodome amounting to about $65 \mathrm{~m}$ in height, suggesting the intrusion of viscous dacitic magma. A series of eruptions and doming activity had gradually decayed since the later half of April and finally stopped their activities in August 2000.

Steaming ground expansion stage - As the eruptive activities have decayed at the Nishiyama craters, a geothermal field has developed around the Nishiyama fault group where has shown no geothermal indications before the eruption. Miura and Niida (2002) and Okazaki et al. (2002) made a modeling to interpret the crustal deformation due to the doming activity. Miura and Niida (2002) estimated that the depth to the top of the intruded magma was approximately $100 \mathrm{~m}$, assuming a sheet shaped dyke intrusion model. Contact of the dyke with plentiful groundwater 
would introduce the violent phreatomagmatic eruptions and the development of the geothermal field. Geothermal activity is still continued and water vapor was discharged in a large area.

\section{Temperature measurements in the Nishiyama geothermal field}

Succeeding the violent eruptions and crustal deformations, volcanic activity of the Usu volcano has shifted to the stage of thermal energy release from the remnant magma, and formed the Nishiyama geothermal field as described above. We measured the ground temperature using thermistor thermometers to monitor the development of the Nishiyama geothermal field. First, measurements were carried out in the whole area of the Nishiyama geothermal field in order to know the general feature of the temperature distribution in October and November 2000. Repeated measurements along the A-B line shown in fig. 3 were performed 3 times in December 2000, October 2001, and March 2002.

\subsection{Ground temperature distribution}

We carried out temperature measurements in $1 \mathrm{~m}$ depth at 131 points in the Nishiyama geothermal field in October and November 2000 (fig. 3) about a half year after the eruption commenced. The most remarkable geothermal anomalies were observed along the main fissure of the Nishiyama fault group and the highest temperature of $100^{\circ} \mathrm{C}$ appeared on the top of the newly formed cryptodome. In addition, the temperature above $100^{\circ} \mathrm{C}$ was observed exceptionally at a fumarole. In addition, the area around the Nishiyama crater group showed a moderately high tem-

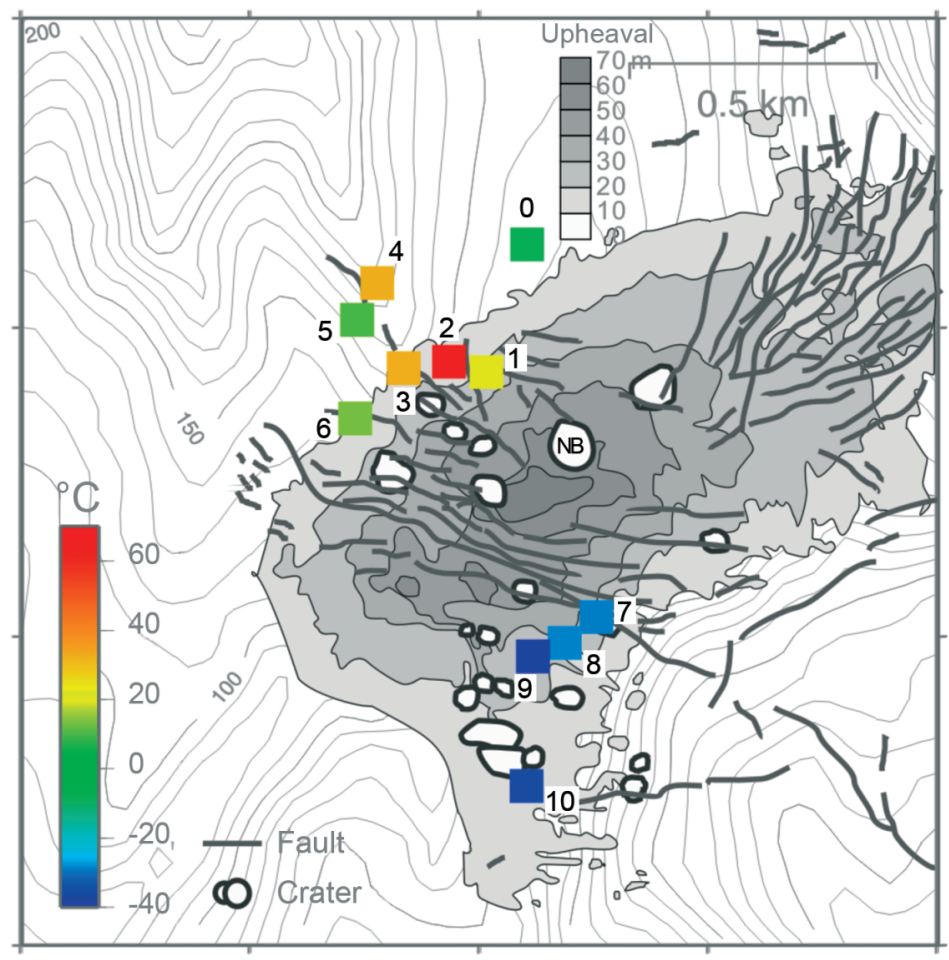

Fig. 4. Time difference of the ground temperature between March, 2002 and October-November, 2000. 
perature of $40-70^{\circ} \mathrm{C}$. On the contrary, only low temperatures of less than $40^{\circ} \mathrm{C}$ were observed around the NB crater, although the crater was the largest and most active one in the Nishiyama crater group.

\subsection{Repeated measurements of the ground temperature}

We carried out repeated measurements at 11 points selected from the points of the first measurement. The difference in temperature between the first measurement and the second one (March, 2002) revealed that the high ground temperature area observed around the cryptodome and the NW edge of the main fault (no. 16) had spread to the NW direction, away from the craters, along the fault (maximum increase: $64^{\circ} \mathrm{C}$ ) as shown in fig. 4 and table I. On the other hand, the ground temperature around the crater group (no. 7-10) had decreased drastically (decrease: about $-30^{\circ} \mathrm{C}$ ).

In addition to the wide area measurements, we carried out repeated measurements along the A-B line (fig. 3) to investigate the features of geothermal field in more detail. The A-B line was taken perpendicularly to the NW-SE trend of the Nishiyama fault group. The measurement was made at $67 \mathrm{~cm}$ depth with a measurement inter-

Table I. Temporal variation of ground temperature. Site numbers correspond with those shown in fig. 4.

\begin{tabular}{cccc}
\hline $\begin{array}{c}\text { Site } \\
\text { number }\end{array}$ & $\begin{array}{c}2000 / \text { October } \\
\left({ }^{\circ} \mathrm{C}\right)\end{array}$ & $\begin{array}{c}2002 / \mathrm{March} \\
\left({ }^{\circ} \mathrm{C}\right)\end{array}$ & $\begin{array}{c}\text { Difference } \\
\left({ }^{\circ} \mathrm{C}\right)\end{array}$ \\
\hline 0 & 13.0 & 5.0 & -8.0 \\
1 & 42.4 & 62.8 & +20.4 \\
2 & 33.7 & 97.6 & +63.9 \\
3 & 50.4 & 83.1 & +32.7 \\
4 & 65.0 & 97.6 & +32.6 \\
5 & 87.9 & 97.6 & +9.7 \\
6 & 30.7 & 43.7 & +13.0 \\
7 & 44.3 & 15.3 & -29.0 \\
8 & 41.4 & 12.7 & -28.7 \\
9 & 52.1 & 14.3 & -37.8 \\
10 & 48.8 & 13.2 & -35.6 \\
\hline
\end{tabular}

val of $5 \mathrm{~m}$. We can see the highest temperature up to the boiling temperature of water $\left(100^{\circ} \mathrm{C}\right)$ around the Nishiyama fault group (between 170$250 \mathrm{~m}$ and around $350 \mathrm{~m}$ in horizontal scale) as shown in fig. 5a. The difference between the ground temperature in October, 2001 and that in December, 2000 revealed a significant increase up to several tens degrees around $150 \mathrm{~m}$ and 320 $\mathrm{m}$ in horizontal scale (fig. 5b). Therefore, geothermal field had spread not only to the NW direction along the Nishiyama faults but also to the perpendicular direction of the faults. Figure $5 \mathrm{~b}$ also shows a small difference between the temperatures in March 2002 and those in October 2001, suggesting that the development of the geothermal field had taken place in an early stage of the geothermal activity.

\section{Self-potential measurements}

The self-potential method has been used to investigate the hydrothermal activity of volcanoes because the groundwater flow generates electric potential field on the Earth's surface based on the electrokinetic effect (e.g., Zlotnicki and Nishida, 2003). In many cases, positive SP anomalies are located on active fissure zones and/or on fumarolic areas. Many authors have interpreted that the anomalies are caused by upward movement of the heated groundwater (e.g., Ishido, 1988; Zlotnicki and Nishida, 2003). We carried out self-potential measurements on the Nishiyama geothermal field using a pair of nonpolarizing $\mathrm{Cu}-\mathrm{CuSO}_{4}$ electrodes and a high impedance digital voltmeter $(10 \sim 100$ mega- $\Omega$ of the input resistance) in order to monitor the evolution of the geothermal activity. The SP survey was carried out three times: in October and November 2000, June 2001 and March 2002. The $\mathrm{SP}$ values are given relative to a reference station $\mathrm{G}$, which was sufficiently far from geothermal indications, as shown in fig. 6a-c. We tried to contact the electrode with the ground as quickly as possible on the geothermal field because the $\mathrm{Cu}-\mathrm{CuSO}_{4}$ electrodes have temperature dependence of about $(-1 \sim+1) \mathrm{mV} /{ }^{\circ} \mathrm{C}$ (Perrier et al., 1998). The electrical potential difference between each measurement point and the station $G$ was measured directly through an electric wire. 
(a)

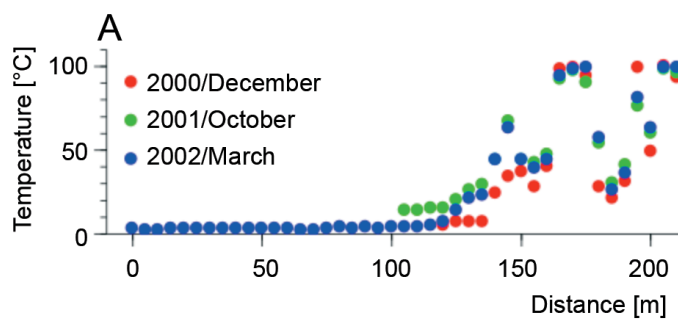

B

(b)

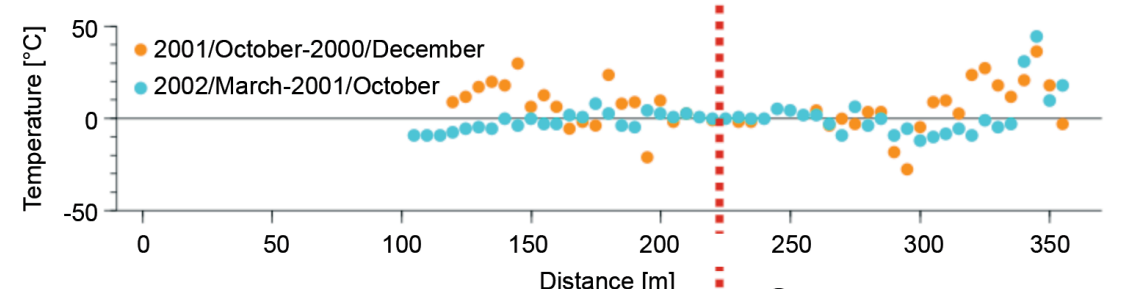

(C)

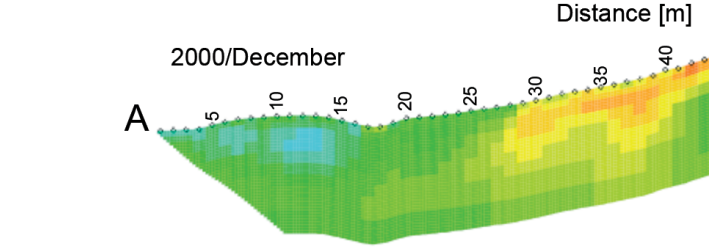

(d) $A$

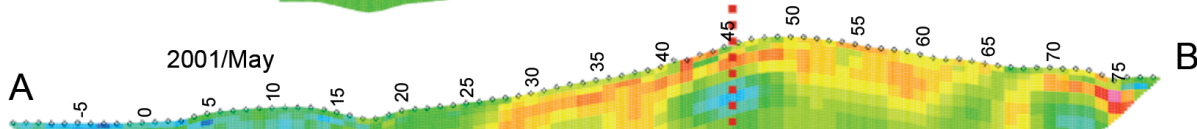

(e)
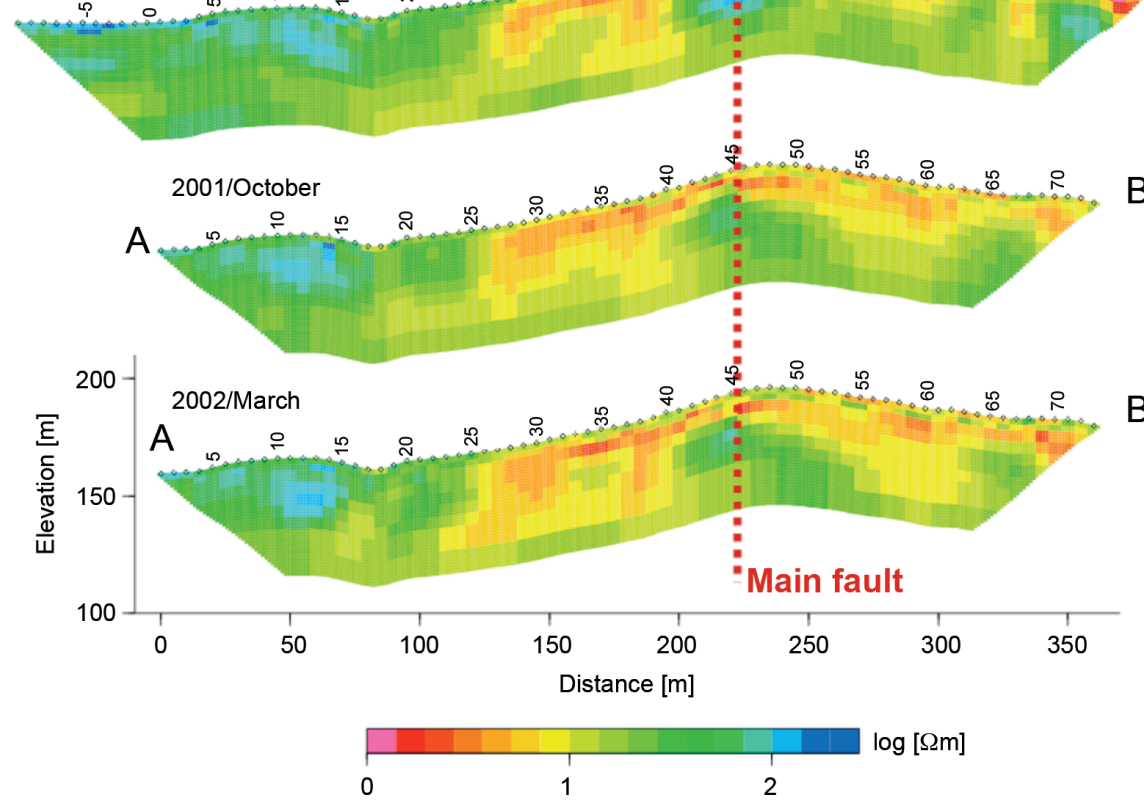

(f)

Fig. 5a-f. a) Ground temperature at a depth of $67 \mathrm{~cm}$ along the measurement line A-B shown in fig. 3; b) temporal variation of the ground temperature along the A-B line; c), d), e) and f) temporal variation of the resistivity structure along the A-B line. Horizontal scale and position are common to all figures. 

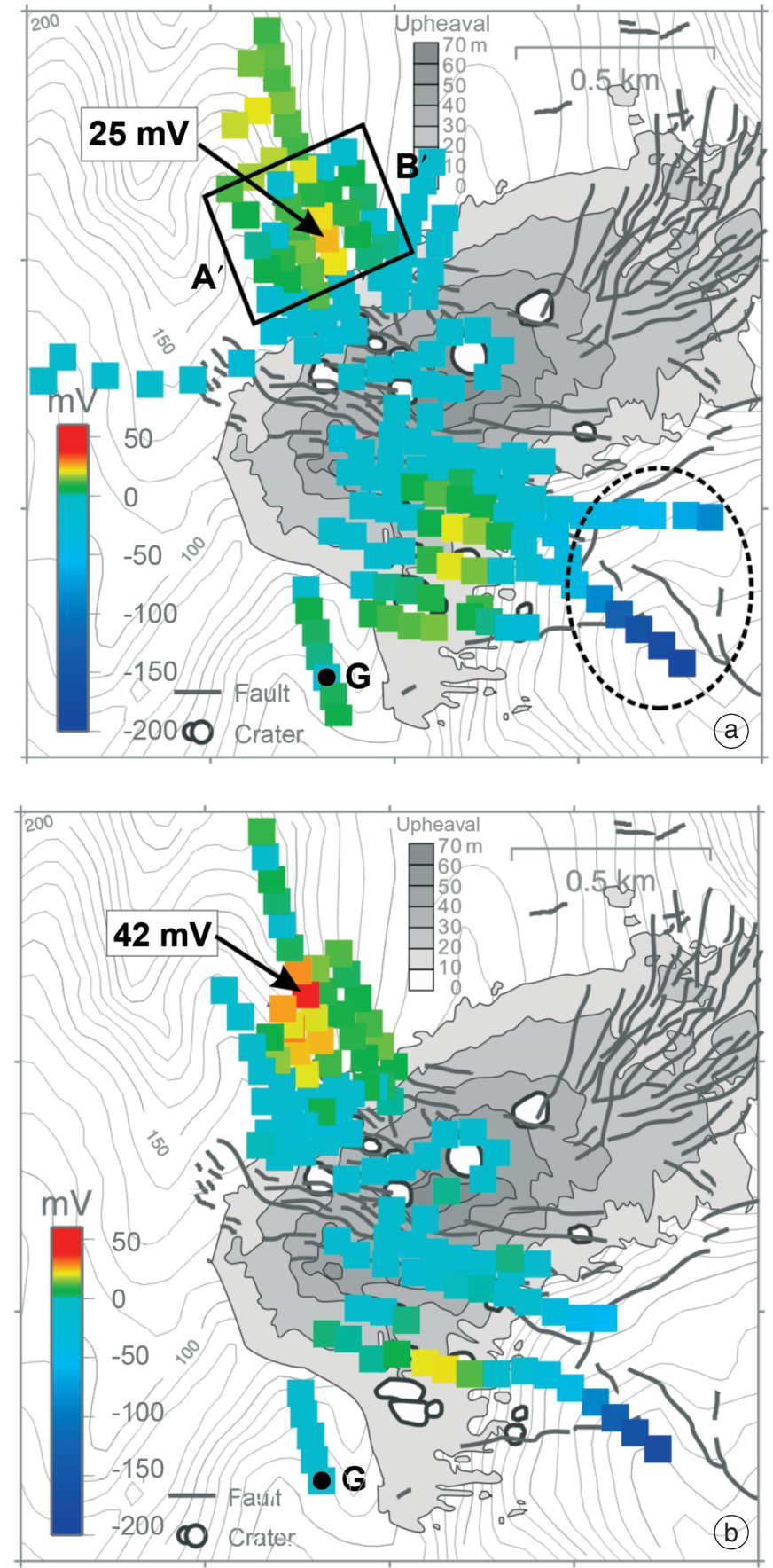

Fig. 6a,b. Temporal variation of self-potential anomalies relative to the reference station G: a) October-November, 2000; b) June, 2001. 


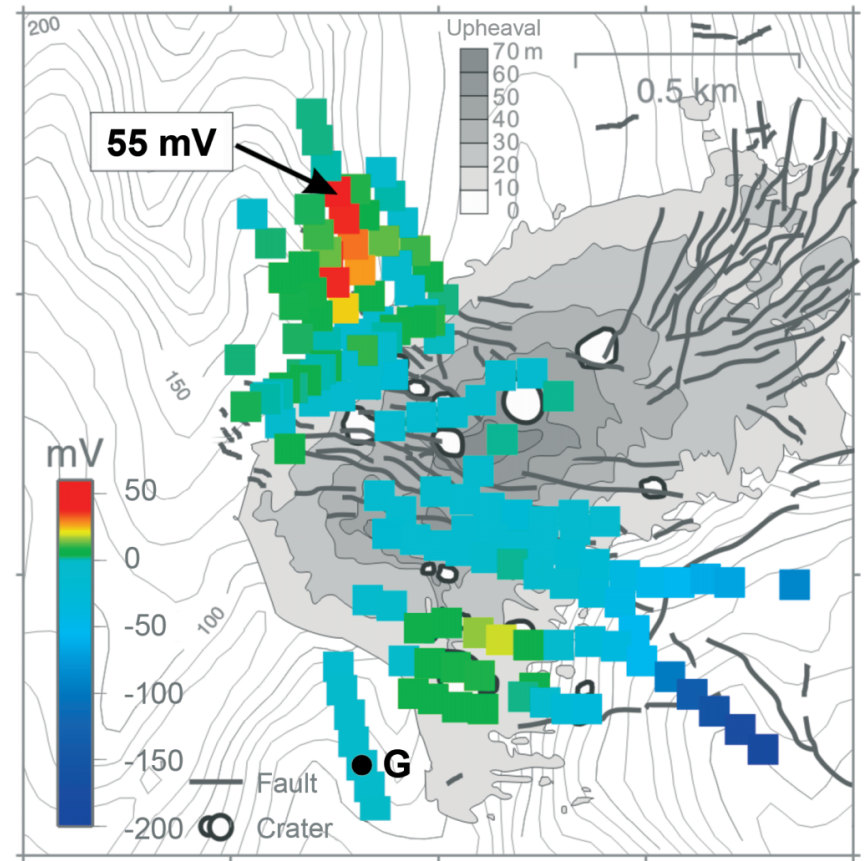

Fig. 6c. Temporal variation of self-potential anomalies relative to the reference station G: March, 2002.

We regarded the potential at each point as a mean value at four points measurements within a radius of about $30 \mathrm{~cm}$ round. The dispersion of the potentials among four points was within $3 \sim 5$ $\mathrm{mV}$ at each point. At the end of the survey, we measured the potential at the side of the reference station $\mathrm{G}$ to check the closure residual and the value was below $3 \mathrm{mV}$.

\subsection{Self-potential distribution}

Negative anomalies distributed on the northwest flank of Nishiyama (a topographic high of the Usu somma) are explained by the topographic effect where the potential decreases when the altitude of the topography increases (about -2.5 $\mathrm{mV} / \mathrm{m}$ in the present case) as shown in fig. 7 (data obtained within dashed ellipsoid in fig. 6a are used). It suggests downward groundwater flow along subsurface layers of Nishiyama (e.g. Ishido, 1988; Zlotnicki and Nishida, 2003).

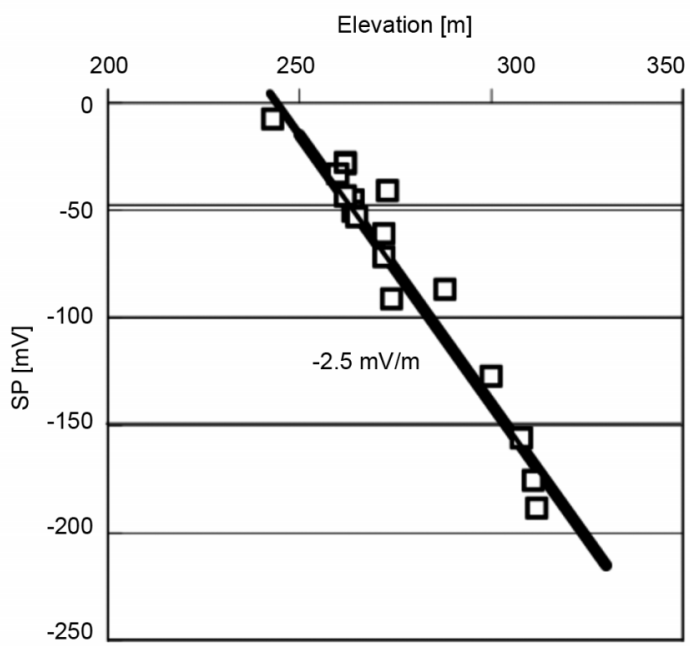

Fig. 7. SP values within a dashed ellipsoid in fig. $6 \mathrm{a}$ are plotted against ground elevation along the NW slope of Nishiyama. A regression line is also shown. 


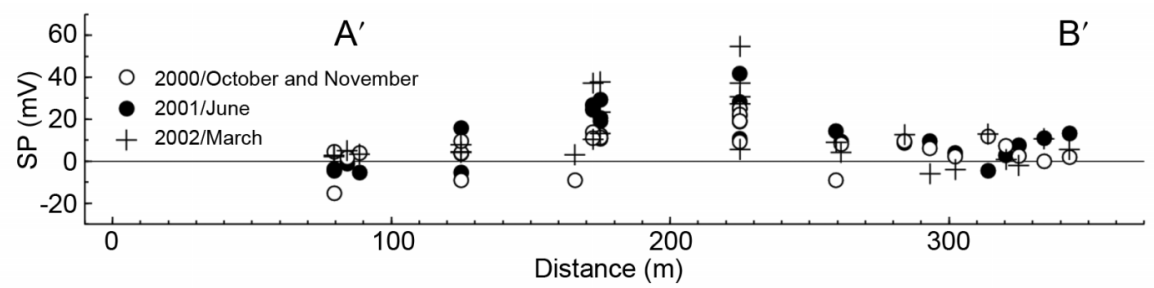

Fig. 8. SP profiles along $\mathrm{A}^{\prime}-\mathrm{B}^{\prime}$ in fig. 6a. Data within a solid square are projected onto the figure.

Positive anomalies up to several tens of $\mathrm{mV}$ were observed around the NW part of the main fault, although the amplitudes were not so conspicuous and were one order smaller than that of other volcanoes such as, e.g., Hawaii (Zablocki, 1976), Usu summit (Nishida and Tomiya, 1987), Piton de la Fournaise (Zlotnicki et al., 1994a), Unzen-Fugendake (Hashimoto and Tanaka, 1995), Miyake-jima (Nishida et al., 1996; Sasai et al., 1997) and so on.

No remarkable anomalies were found around the Nishiyama crater group. Although it is difficult to understand why only small anomalies appear on the newly formed craters, we present two reasons which may explain this phenomenon: 1) thick clayed ash deposits characterized by low resistivity overlie the Nishiyama crater area (about several tens meters in maximum thickness). 2) Choking of the near surface craters by ash deposition tends to prevent the release of the hot volcanic gas to the air (Zlotnicki et al., 1994b) and plenty of groundwater transports thermal energy rapidly along the Nishiyama faults to form positive anomalies not on the crater group but on the Nishiyama geothermal field. This scenario can also explain the rapid decrease of the ground activity in the Nishiyama crater groups.

\subsection{Temporal variation of $S P$}

A small amplitude of the positive anomaly was observed around the NW edge of the Nishiyama fault group $(25 \mathrm{mV})$ at an early stage of geothermal activities (October and November 2000) as shown in fig. 6a. The place of maximum amplitude migrated one hundred and a few meters to NW direction along the faults and its amplitude increased to $42 \mathrm{mV}$ in July 2001 and $55 \mathrm{mV}$ in March 2002 following the spread of the high ground temperature zone as mentioned in Section 3.1. (fig. 6b,c). A cross section of the SP anomalies along $\mathrm{A}^{\prime}-\mathrm{B}^{\prime}$ (fig. 6a) is shown in fig. 8. Spatial wavelength of the positive anomalies is roughly less than two hundred meters, suggesting the hydrothermal system is confined within a shallower depth.

\section{Electrical resitivitiy survey}

Electrical resistivity surveys have an advantage of sensing the aspects of hydrothermal systems in volcanic regions because the electrical resistivity of rocks strongly depends on the content of water, the temperature, and so on. We carried out a two dimensional electrical resitivity survey along the A-B line crossing the high temperature area. We used both the dipole-dipole and the Wenner array because sensitivity for a subsurface structure is different each other. Table II summarises the specifications of the survey and modeling: total measurement lengths, electrode spaces, and electrode arrangements for measurements are shown. The electrode array was moving along the line at every $5 \mathrm{~m}$. The apparent resistivities measured by each electrode spacing at every place were used to invert the two dimensional (2D) resistivity model. We made measurements four times (December 2000; May 2001; October 2001; March 2002) and constructed detailed 2D model structures using the smoothnessconstrained 2D inversion for DC resistivity data by ABIC (Akaike's Bayesian Information Criterion) minimization method (Uchida, 1993). The effect of the topography is included in the model. 
Table II. The specifications of the electrical sounding and modeling.

\begin{tabular}{|c|c|c|c|c|c|c|c|c|}
\hline Date & $\begin{array}{l}\text { Measurement } \\
\text { lenght }(\mathrm{m})\end{array}$ & $\begin{array}{l}\text { Electrode } \\
\text { arrangement }\end{array}$ & $\begin{array}{l}\text { Electrode } \\
\text { spacing }(\mathrm{m})\end{array}$ & $\begin{array}{c}\text { Number } \\
\text { of input } \\
\text { data }\end{array}$ & $\begin{array}{l}\text { Number } \\
\text { of model } \\
\text { parameter }\end{array}$ & $\begin{array}{l}\text { RMS } \\
\text { mis fit }\end{array}$ & $\begin{array}{l}\text { Smoothing } \\
\text { factor }\end{array}$ & $\begin{array}{l}\text { Figure } \\
\text { number }\end{array}$ \\
\hline $\begin{array}{l}2000 / \\
\text { December }\end{array}$ & 360 & $\begin{array}{l}\text { Dipole/Dipo } \\
\text { Wenner }\end{array}$ & & $\begin{array}{l}58 \\
14\end{array}$ & 619 & 11.43 & 47.568 & fig. $5 \mathrm{c}$ \\
\hline $\begin{array}{l}\text { 2001/ } \\
\text { May }\end{array}$ & 440 & $\begin{array}{l}\text { Dipole/Dipole } \\
\text { Wenner }\end{array}$ & $\begin{array}{l}5,10,15, \ldots, 95 \\
5,10,15, \ldots, 95\end{array}$ & $\begin{array}{l}1005 \\
1005\end{array}$ & 755 & 5.24 & 14.142 & fig. $5 d$ \\
\hline $\begin{array}{l}\text { 2001/ } \\
\text { October }\end{array}$ & 360 & $\begin{array}{l}\text { Dipole/Dipole } \\
\text { Wenner }\end{array}$ & $\begin{array}{l}5,10,15,20,30,40,60,80 \\
5,10,15,20,30,40,60,80\end{array}$ & $\begin{array}{l}690 \\
174\end{array}$ & 619 & 5.51 & 11.892 & fig. $5 \mathrm{e}$ \\
\hline $\begin{array}{l}\text { 2001/ } \\
\text { March }\end{array}$ & 360 & $\begin{array}{l}\text { Dipole/Dipole } \\
\text { Wenner }\end{array}$ & $\begin{array}{l}5,10,15,20,30,40,60,80 \\
5,10,15,20,30,40,60,80\end{array}$ & $\begin{array}{l}690 \\
174\end{array}$ & 619 & 6.21 & 11.892 & fig. $5 f$ \\
\hline
\end{tabular}

The number of data for each modeling is also shown in table II with RMS misfit and number of meshes.

\subsection{Resistivity structure of the geothermal region}

Resistivity soundings made in December 2000 (fig. 5c) revealed that the surface low resistive layer (nearly $10 \Omega-\mathrm{m}$ ) to a depth of about $20 \mathrm{~m}$ was distributed in the high ground temperature zone shown in fig. 5a (electrode numbers: 28-66 and 71-73). The relatively high resistive part (about $100 \Omega$-m) underlay the surface low resistive layer around the main fault. This resistive part is probably indication of the zone involving partially the dry steam phase. Temperature above $100^{\circ} \mathrm{C}$ observed at a fumarole in October 2000 was a direct evidence of the superheated steam zone. Rising hot steam was limited in its movement by the relatively low temperature surface in such a way that condensation took place and a surface layer was saturated with liquid water from condensation and rainfall. Such highly resistive zones were also detected beneath the fractures formed at the time of the 1977-1978 eruption of the Usu volcano and were explained as being due to rising dry steam (Ballestracci and Nishida, 1987).

A region of electrode numbers 1-25 showed the resistivity of a few tens to hundred $\Omega-\mathrm{m}$. As no manifestation of anomalous ground temperature was seen there, the resistivity values of this region might show original ones not influenced by the present geothermal activity.

\subsection{Temporal variation of the resistivity structure}

Repeated electrical surveys revealed drastic changes in the resistivity structure in the short term of about 15 month as shown in fig. 5c-f. Following the spread of high ground temperature zone (fig. 5b), the low resistive layer around electrode numbers 30 and 70 expanded horizontally to the normal resistivity area which had been saved from the influence of the geothermal activity.

The surface low resistive layer has gradually invaded the underlying high resistive layer, which probably originated partially from the dry steam phase, especially around electrode numbers 2540 and 55-65. In other words, the high resistive part has shrunk depending on the progress of heat discharge to the surroundings and the air.

\section{A scenario of development of the geothermal field}

The results of observations are summarized as follows: 
1) The geothermal field migrated along the Nishiyama main fault, away from the creaters.

2) Positive SP anomalies also migrated following the migration of the geothermal field. Typical topographic effect of the SP field was observed along the slope of Nishiyama, suggesting the existence of the potential flow.

3) A remarkable decrease of ground temperature was observed on the Nishiyama crater group at an early stage after cease of the eruptive activities.

4) A relatively high resistivity zone was observed beneath the high ground temperature zone. This resistive zone is thought to partially include the dry steam phase.

5) The area of the resistive zone has shrunk as time passed, suggesting the vapor phase has altered to the high temperature liquid phase.

Based on the above-mentioned results, we draw a scenario of development of the geothermal field. We assume that plentiful ground water flows down along subsurface layers of the Nishiyama slope as the potential flow. This was suggested by the presence of the highly permeable basaltic somma lava with the permeability of $10^{-10}$ to $10^{-12} \mathrm{~m}^{2}$ in wells drilled for hot spring explorations (Oshima and Matsushima, 1999; Matsushima, 2003). The enormous topographic effect of the SP field is also the supporting factor of the downward groundwater flow (fig. 7). Contact of the groundwater with intruded magma is considered to be the cause of the phreatomagmatic eruptions.

During the final stage of the eruptive activities, thermal energy release by steam had become enormous on the NB crater and other craters as shown in fig. 9 (stage 1). Choking of the near surface craters by ash deposition may prevent the release of the hot steam to the air and the groundwater transported the thermal energy rapidly along the Nishiyama faults to form geothermal field not on the crater group but on the Nishiyama geothermal field (stage 2 ). This scenario can be interpreted as the rapid decrease of the ground temperature in the Nishiyama crater group area (decrease: about $-30^{\circ} \mathrm{C}$ ). The potential flow from the Nishiyama slope and faults is expected to play important roles for rapid evolution of the geothermal field. Prior to the expansion of the geothermal
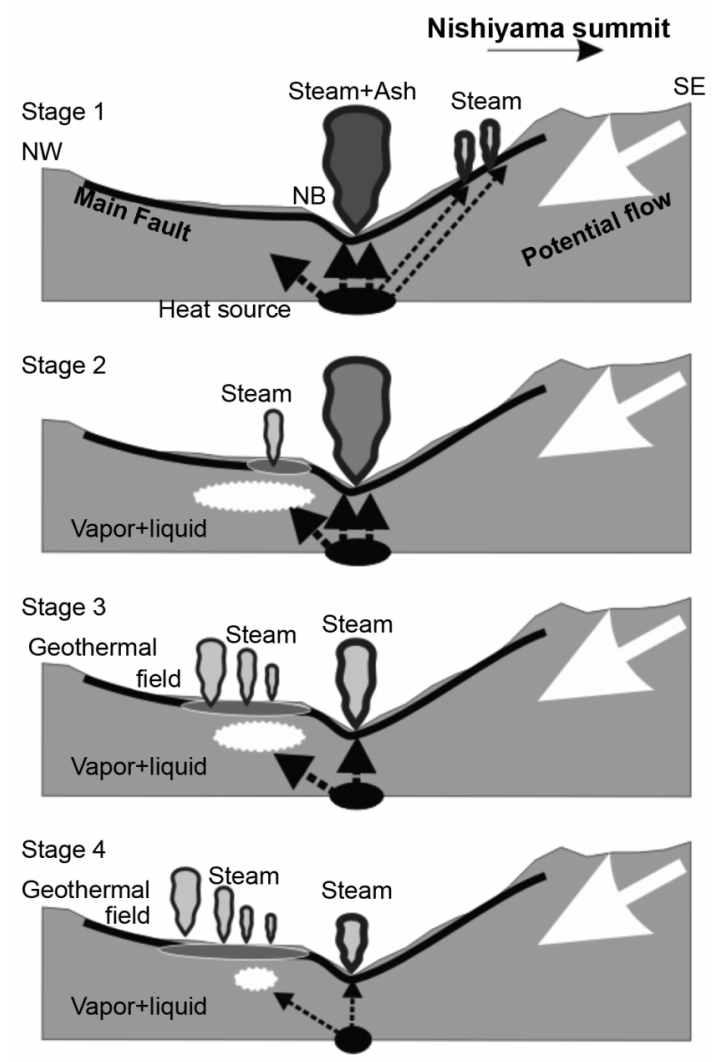

Fig. 9. Schematic models of evolution of the geothermal activities. Thickness of arrows depend qualitatively on assumptions of the thermal energy supply from the intruded magma. Height of steam is also shown qualitatively.

field, it is thought that a zone involving the dry steam phase had been formed beneath the Nishiyama fault group at least in December 2000 because the high resistive layer, probably caused by the presence of the dry steam phase, was detected (fig. 5c). Subsequent development of the process had formed the geothermal field around the cryptodome and the NW edge of the main fault of the Nishiyama fault group (maximum increase of the ground temperature: $64^{\circ} \mathrm{C}$ ) (stages 3 and 4 ), because the high resistive part had shrunk depending on the progress of heat discharge to the surroundings and the air. 


\section{Conclusions}

A geothermal field developed in 2000 on the foot of the Usu volcano where showed no geothermal indication in the past. We conducted geophysical measurements to clarify the evolution of the geothermal field, especially in the early stage of the geothermal activity. The results of observations are summarized as follows:

1) A remarkable decrease of ground temperature was observed on the Nishiyama crater group at an early stage after cease of the eruptive activities.

2) The geothermal field has migrated along the Nishiyama main fault, away from the craters.

3) Positive SP anomalies have also migrated following the migration of the geothermal field.

4) The topographic effect of the SP field was observed along the slope of the Usu somma, suggesting the existence of downward potential flow.

5) Drastic changes in the subsurface resistivity structure were accompanied by the rapid expansion of the geothermal field.

Considering the highly permeable Usu somma and the topographic effect of the SP field, the potential flow through the newly formed faults must play an important role for rapid expansion of the geothermal field and migration of the most active part.

\section{Acknowledgements}

We are extremely grateful to Hiromitsu Oshima, Atsuo Suzuki, Yasuhiro Sugisaki, Kengo Tanimoto, Shin Tamura, Mikio Oomae, Tomohiro Watanabe and Shinako Noguchi for kind help in the course of observation. Two anonymous referees provided useful review comments to complete the manuscript.

\section{REFERENCES}

BALlestracci, R. and Y. NishidA (1987): Fracturing associated with 1977-1978 eruption of Usu volcano, North Japan, as revealed by geophysical measurements, $J$. Volcanol. Geotherm. Res., 34, 107-121.
HASHIMOTO, T. and Y. TANAKA (1995): A large self-potential anomaly on Unzen volcano, Shimabara Peninsula, Kyushu Island, Japan, Geophys. Res. Lett., 22, 191-194.

IsHiDO, T. (1988): Self-potential generation by subsurface water flow through electrokinetic coupling, in Detection of Subsurface Flow Phenomena (Springer-Verlag) edited by G.P. Merkler, H. Militzer, H. Hötzl, H. ARMBruster and J. BRAUns, Lecture Notes in Earth Sci., 27, 121-131.

Matsushima, N. (1992): Geothermal study on active volcano with special attention to the heat discharge process accompanied by the 1977 eruption of Usu volcano, Ph.D. Thesis (Hokkaido University, Sapporo), (in Japanese).

Matsushima, N. (2003): Mathematical simulation of magma-hydrothermal activity associated with the 1977 eruption of Usu volcano, Earth Planets Space, 55, 559568.

MiurA, D. and K. NiIDA (2002): Two-stage Growth Model of Cryptodome by Shallow Intrusions, the 2000 Eruption of Usu volcano, Northern Japan, J. Bull. Volcanol. Soc. Jpn. Ser. 2 , 47 ,119-130 (in Japanese with English abstract).

Nakagawa, M., A. Matsumoto, J. Tajika, W. Hirose and T. OHTSU (2005): Re-investigation of eruption history of Usu volcano, Japan: finding of pre-Meiwa eruption (late 17th century) between Kanbun (1663) and Meiwa (1769) eruptions, Bull. Volcanol. Soc. Jpn., 50, 39-52 (in Japanese with English abstract).

NishidA, Y. and H. TomiYA (1987): Self-potential studies in volcanic areas, 1. Usu volcano, J. Fac. Sci. Hokkaido Univ. Ser. 7, 8, 173-190.

Nishida, Y., H. SATO, M. Utsugi, H. Murakami, K. Amita, H. Tanaka, J. Zlotnicki, P. Yvetot, P, Morat, Y. SASAI and Y. ISHIKAWA (1996): A preliminary report on the distribution of the self potential field in Miyake-jima volcano, in Proceedings of the Conductivity Anomaly Symposium, 247-253 (in Japanese).

OKazaki, N., H. Takahashi, M. Kasahara, S. Ishimaru, H. Mori, S. Kitagawa, K. Fujiwara and M. Churei (2002): Crustal deformation associated with the 2000 eruption of Usu volcano as observed by a dense GPS array, Bull. Volcanol. Soc. Jpn., 47, 547-557 (in Japanese with English abstract).

Oshima, H. and N. Matsushima (1999): Preliminary report on hydrological environment in the shallow part of Usu volcano, Geophys. Bull. Hokkaido Univ., 62, 79-97 (in Japanese with English abstract).

Perrier, F., G. Petiau, M. Valiant, G. Clerc, D. MasciMENTO and O. YAZICI-CAKIN (1998): The measurement of electrode parameters in the laboratory, in The Garchy 1995-1996 Electrode Experiment Technical Report (CNRS Garchy), edited by G. Clerc, G. Petiau and F. PERRIER, 93-114.

Sasai, Y., J. Zlotnicki, Y. Nishida, P. Yvetot, P. Morat, H. Murakami, Y. TANAKA, Y. IshiKaWA, S. KoYAma and W. SEKIGUCHI (1997): Electromagnetic monitoring of Miyake-jima volcano, Izu-Bonin Arc, Japan: a preliminary report, J. Geomag. Geoelectr., 49, 1293-1316.

ToKAREV, P.I. (1967): The giant eruption of the Shevluch on November 12, 1914 and its forerunners, Izv. Earth Phys., 9, 572-579.

UCHIDA, T. (1993): Smoothness-constrained 2D inversion 
for DC resistivity data by ABIC minimization method, Butsuri-Tansa (Gephys. Explor.), 46, 105-119 (in Japanese with English abstract).

Ui, T., M. Nakagawa, C. Inaba, M. Yoshimoto and Joint RESEARCH GROUP FOR THE 2000 ERUPTION (GEOLOGICAL PARTY) (2002): Sequence of the 2000 Eruption, Usu volcano, Bull. Volcanol. Soc. Jpn. Ser. 2, 47,105117 (in Japanese with English abstract).

YoKoYAMA, I. (1957): Energetics in active volcanoes, Bull. Earthquake Res. Inst., Univ. Tokyo, 35, 75-97.

ZABLOCKI, C.J. (1976): Mapping thermal anomalies on an active volcano by the self potential method, Kilauea, Hawaii, in Proceedings of 2nd U.N. Symposium on the Development and Use of Geothermal Resources, San Francisco, 2, 1299-1309.

ZLOTNICKI, J. and Y. NisHidA (2003): Review on morpho- logical insights of self-potential anomalies on volcanoe, Surv. Geophys., 24, 291-338.

Zlotnicki, J., S. Michel and C. AnNen (1994a): Self-potential anomalies and convective systems on la Fournaise volcano (Reunion Island, France), C.R. Acad. Sci. Paris Ser. II, 318, 1325-1331 (in French with extended English abstract).

Zlotnicki, J., M. Feuillard and G. Hammouya (1994b): Water circulation on La Soufriere volcano (Guadeloupe, Lesser Antilles): May-December 1992 seismovolcanic crisis. Renew of volcanic activity?, J. Geomag. Geoelectr., 46, 797-813.

ZoHDY, A.A.R., L.A. ANDERSON and L.J.P. MufFLER (1973): Resistivity, self-potential, and induced-polarization surveys of a vapor-dominated geothermal system, Geophysics, 38, 1130-144. 